\title{
Complexity of relationship between 2D/3D urban morphology and land surface temperature: A multi- scale perspective
}

Yu Liu

Shandong Normal University

\section{Zhipeng Wang}

Shandong land development group

Xuan Liu

Shandong land development group

Baolei Zhang ( $\sim$ blzhangsd@163.com )

Shandong Normal University https://orcid.org/0000-0001-8866-6728

\section{Research Article}

Keywords:

Posted Date: May 3rd, 2021

DOI: https://doi.org/10.21203/rs.3.rs-382333/v1

License: (9) This work is licensed under a Creative Commons Attribution 4.0 International License.

Read Full License

Version of Record: A version of this preprint was published at Environmental Science and Pollution Research on July 8th, 2021. See the published version at https://doi.org/10.1007/s11356-021-15177-7. 


\title{
Complexity of relationship between 2D/3D urban morphology and land surface temperature: A multi-scale perspective
}

\author{
Yu Liu'. Zhipeng Wang ${ }^{2}$. Xuan Liu². Baolei Zhang ${ }^{1 *}$
}

(1. School of Geography and Environment, Shandong Normal University, Jinan 250014, China)

(2. Shandong Land Development Group Co., Ltd., Jinan 250014, China)

\begin{abstract}
Urban morphology is a crucial contributor to urban heat island (UHI) effects. However, few studies have explored the complex effect of 2D/3D urban morphology on UHI from a multiscale perspective. In this study, We chose the central area of Jinan city, which was commonly known as the "furnace", as the case study area. novel 2D/3D urban morphology indexes-building coverage ratio (BCR)(for assessing the 2D building density), building volume density (BVD)( for assessing the 3D building density), and the frontal area index (FAI)(for assessing 3D ventilation conditions) were calculated and derived to investigated complexity of relationship between $2 \mathrm{D} / 3 \mathrm{D}$ urban morphology and land surface temperature(LST) at different scales using the maximum information coefficient (MIC) and geographically weighted regression (GWR). The results indicated that (1) These newly 2D/3D urban morphology indexes as essential factors that are responsible for LST variation, BCR is the most important urban morphology index affecting the LST, followed by BVD and FAI. Importantly, the relationship between the BCR, BVD, and FAI and the LST was an inverse U-shaped curve. (2) The relationship between 2D/3D urban morphology and LST variation showed a significant scale effect. With increased grid size, the correlation between the BCR, BVD, and FAI and the LST strengthened, "inflection point" of inverse U-shaped curve was significantly declined, and their explanation rate to LST first increased and then decreased, with a maximum value at the 700-m scale. Additionally, the FAI exerted a stronger negative effect, while the BCR and BVD generally had stronger positive effects on LST as the grid size increasing. This study extends our scientific understanding of the complexity effect of urban morphology on LST and is of great practical significance for urban thermal environment regulation at multi-scale.
\end{abstract}

Keywords: 2D/3D urban morphology; land surface temperature; multi-scale; complex relationship; Jinan city

\section{Introduction}

In recent decades, the world has experienced explosive population growth and urban sprawl (Seto et al. 2012). The increase in building surface area and complex morphology has modified the surface physical properties and heat storage capacity, in turn dramatically altering the thermal environment (Grimm et al. 2008, Liu et al. 2020, Tiatragul et al. 2017). A well-documented consequence of urban thermal environment change is the formation of the urban heat island (UHI) effect, which can have profound impacts on water and air quality, urban public health, energy consumption, and vegetation phenology (Coseo \&Larsen 2019, Inouye 2015, Kolokotroni et al. 2007, Taha 1997, Voogt \&Oke 2003). Hence, the topic of the urban thermal environment has raised significant concerns among many related research fields (Wang et al. 2020, Yu et al. 2019).

The UHI effect can be assessed by either air temperature or land surface temperature (LST), in which LST is considered to correspond closely with the canopy layer UHI and has been widely used in studying the surface UHI (SUHI) effect (Weng 2009). It is largely recognized that satellite-based

\footnotetext{
* Corresponding author.

E-mail addresses: blzhangsd@163.com (B. Zhang).
} 
remote sensing techniques are able to provide spatially continuous coverage of LST in a time- and cost-efficient manner (Huang \&Wang 2019a), and these techniques can provide urban morphology information (e.g., urban structure types, landscape patterns, settlement density). Therefore, LST has been widely used to investigate the relations between the SUHI effect and urban morphology indicators (e.g., land-cover/use types, landscape patterns) (Carmona et al. 2017, Zhou et al. 2017).

It has been stressed that urban morphology is the main driver of LST change, particularly at local spatial scales (Chen et al. 2006, Yao et al. 2019). In this context, the effects of two-dimensional (2D) urban morphology indexes on LST or the SUHI effect have been noted by many studies (Giridharan et al. 2007, Luxmoore et al. 2005, Stefania \&Chaiyapon 2018, Wang et al. 2019). Although three-dimensional (3D) urban morphology is a key component of urban construction and an important driving factor of LST, only a few scholars have investigated the effects of 3D urban morphology on LST, such as studies of urban building height (UBH), sky view factor (SVF), frontal area index (FAI), and building volume density (BVD) (Ivajnsic et al. 2014, Youpei et al. 2016, Zhu et al. 2003). Scholars have tried to examine the influencing characteristics of the $2 \mathrm{D}$ and $3 \mathrm{D}$ urban morphology index on LST (Wang et al. 2016, Yang et al. 2010). Therefore, there is an urgent need for us to investigate the comprehensive effects of 2D/3D urban morphology on LST.

The characteristics of the pattern and process of geographical research, such as the occurrence, spatiotemporal distribution and mutual coupling, are scale dependent; that is, some relationships within geographical objects may be shown only on a certain scale (Wu 2004). Therefore, scale analysis is the basis and premise of exploring the driving forces of the urban thermal environment. Previous studies have revealed that the spatial pattern of LST, as well as its driving factors, has multiscale features, implying that the spatial scales of different types of 2D/3D urban morphology in LST studies are likely to be different (Levin et al. 1992, Wu 2004). A rough scale is beneficial for assessing the overall situation, while a finer scale has the effect of enlarging the details, and at a certain scale, the correlation of the phenomenon factors may be strongest. The phenomenon of scale effect issues stems from calculation units, but the optimal or proper analytical unit to study the relationship between LST and urban morphology has not been explicitly addressed (Yang et al. 2019a).

This study aimed to comprehensively explore the complex relationship between 2D/3D urban morphology and urban LST at different spatial scales using the maximum information coefficient (MIC) and geographically weighted regression (GWR) methods. Particularly, the main objectives of this study were to (1) use the MIC and GWR to clarify the complex influence characteristics of the individual urban morphology index on LST and (2) utilize multi-scale analysis to investigate the scale effects of the 2D/3D urban morphology index on LST. We hope that this study can extend our scientific understanding of the effects of urban morphology on LST and UHI mitigation practices.

\section{Methodology}

\subsection{Study area}

Jinan city, located in the middle of the North China Plain, is the capital city of Shandong Province and the central city in the southern wing of the Bohai Sea Rim area. It is a semi-enclosed city surrounded by the Yellow River in the north and Qianfo Mountain in the south (Yang et al. 2020). It has a typical warm temperature, semi-humid and continental monsoon climate, and welldefined seasons. The mean annual temperature is $14^{\circ} \mathrm{C}$, and the average mean precipitation is 650 $700 \mathrm{~mm}$. Jinan is known as the spring city for its large number of parks with the theme of spring 
water. Jinan is also one of China's hottest cities in summer and is commonly known as the "furnace". Jinan has jurisdiction over 12 administrative districts, including 10 municipal districts and 2 counties. The research area of this study was the central area of Jinan (Figure 1), which covers an area of 536 $\mathrm{km}^{2}$ and has an approximate population of 5.96 million.

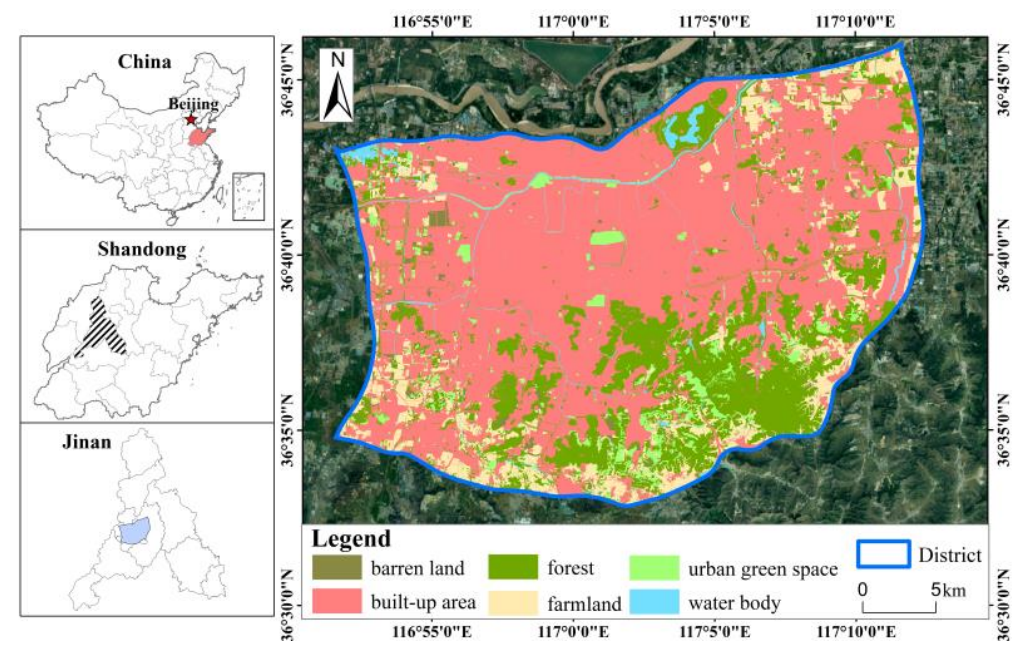

Fig. 1 Map of the study area

\subsection{Data and pre-processing}

Landsat 8 OLI imagery (at the path/row of 122/35) was used to extract LST data. The OLI imagery was obtained from the United States Geological Survey (USGS) (https://earthexplorer.usgs.gov/), and the acquisition time was May 22, 2018. It was almost cloudfree (maximum cloud volume reached only $0.3 \%$ ), and the pre-processing of imagery was mainly completed by ENVI5.3 software, including the radiation calibration and atmospheric correction of Landsat 8 multispectral data (eliminating the errors caused by the sensor itself and those caused by atmospheric scattering, absorption, and reflection), the radiation calibration of Landsat 8 thermal infrared data, and the cutting of the main urban area of Jinan city.

The daily wind data of Jinan in May 2018, which were used to calculate the FAI, were provided by the China Meteorological Administration. Building outline data from 2018 were used to calculate 2D/3D urban morphology indexes, and there were 123,485 building records (including building outline and building floor number information) in the main urban area of Jinan(Figure 2); these data were obtained from a data application website (https://metrodata.jinshuju.com/f/KhU3q5).

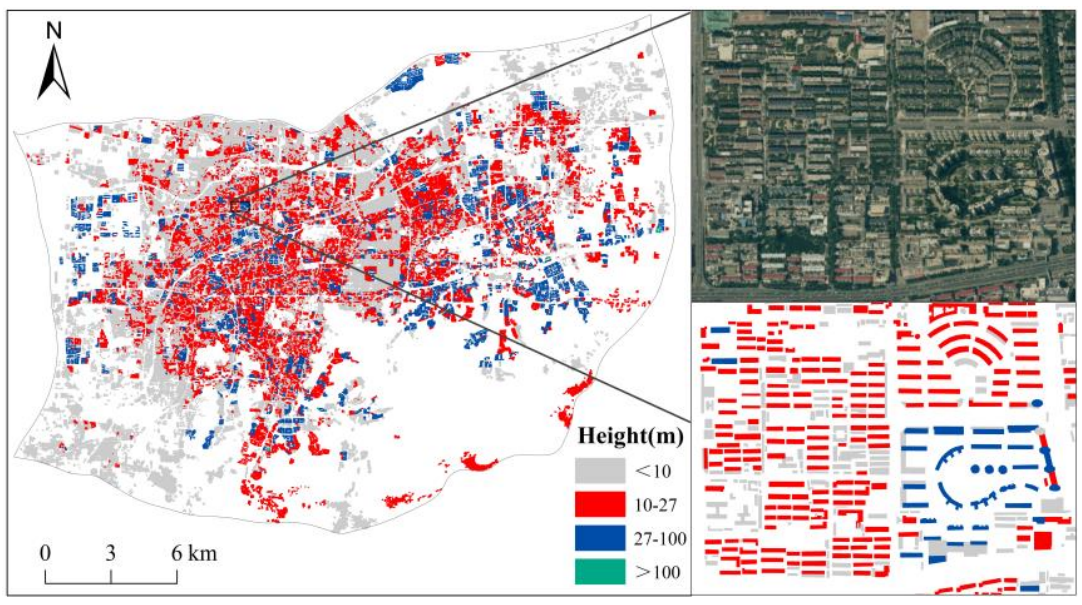

Fig. 2 3D spatial distribution of buildings 


\subsection{Method}

\subsubsection{Land surface temperature (LST) retrieval}

Surface thermal radiation recorded by spectral bands of the Thermal Infra-Red Sensor (TIRS) 10 in Landsat 8 was adopted to retrieve LST (unit: ${ }^{\circ} \mathrm{C}$ ) based on a single-window algorithm (Tu et al. 2016, Wang et al. 2015). This method considers parameters including atmospheric transmittance $(\tau)$, brightness temperature $\left(T_{10}\right)$, mean atmospheric temperature $\left(T_{a}\right)$ and land surface emissivity $(\varepsilon)$ by using Equations (1-3):

$$
\begin{gathered}
T_{s}=\left\{a(1-C-D)+[b(1-C-D)+C+D] * T_{10}-D T_{a}\right\} / C \\
C=\tau \varepsilon \\
D=(1-\tau)[(1-\varepsilon) \tau]
\end{gathered}
$$

where $a$ and $b$ are coefficients obtained from the relationship between thermal radiation intensity and brightness temperature, $a=-70.1775, b=0.4581$. Atmospheric transmittance $(\tau)$ was obtained from the National Aeronautics and Space Administration (NASA, http://atmcorr.gsfc.nasa.gov) by inputting imaging time, central longitude, latitude and other relevant parameters.

To verify the accuracy of the surface temperature, we downloaded the MOD11A surface temperature data from the NASA official website (https://ladsweb.modaps.eosdis.nasa.gov) and compared it with LST retrieval results. The error was less than 5\%, and the calculated LST reflected the spatial distribution of the LST in the study area. Figure 3 shows the retrieved LST map.

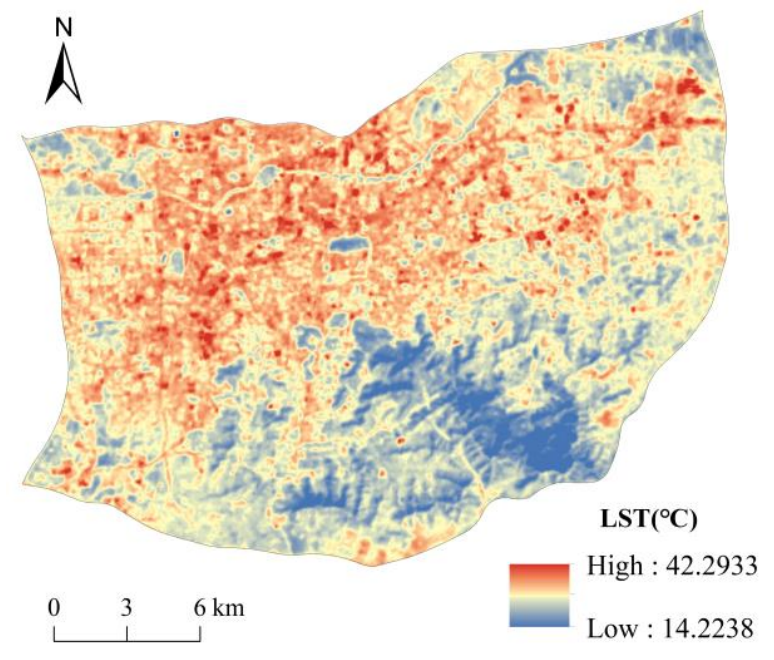

Fig. 3 The sketch map of the overall LST distribution in the study area

\subsubsection{Derivation of 2D/3D urban morphology indexes}

A set of 2D/3D urban morphology indexes was then calculated within each grid cell according to the 3D building information from the satellite data. The "2D urban morphology" in this study included the building coverage ratio (BCR), and the "3D urban morphology" consisted of the (BVD and the FAI.

\section{(1) Building coverage ratio (BCR)}

In this study, the BCR reflects a building's footprint area over the site's area (Yu et al. 2010), and it is calculated as follows:

$$
B C R=\sum_{n=1}^{N} C_{i} / S_{l}
$$

where $C_{i}$ reflects the coverage area of building $i, S_{l}$ is the size of the land lot, and $N$ is the total number of buildings on the land lot. Importantly, the number of buildings $(N)$ may be different 
between the satellite data and the actual data within the same land lot, and the land lot size should be fixed with hundreds of square metres for validation.

\section{(2) Building volume density (BVD)}

BVD is an index used to quantify the building density over a site's area (Petralli et al. 2014), and it is calculated as follows:

$$
B V D=\frac{\sum_{n=1}^{N}\left(C_{i} \times H_{i}\right)}{S_{l}}
$$

where $C_{i}$ reflects the coverage area of building $i, H_{i}$ is the height of building $i, S_{L}$ is the size of the land lot, and $N$ is the total number of buildings on that lot. The BVD value is highly dependent on the size of the land lot $\left(S_{L}\right)$, and its unit is $\mathrm{m}^{3} \mathrm{~m}^{-2}$.

\section{(3) Frontal area index (FAI)}

The equation for calculating the FAI (Wong et al. 2010) is as follows:

$$
\lambda_{f(\theta)}=A(\theta) / A_{\text {plane }}
$$

where $\theta$ represents the wind direction angle, $A(\theta)$ represents the projected area of the building in a specific wind direction, and the $A_{\text {plane }}$ represents the area of the calculation unit. The larger the value of $\lambda_{f(\theta)}$ is, the greater the hindrance to the wind. The value of $\lambda_{f(\theta)}$ varies with different wind directions.

To objectively reflect the obstructive effect of buildings on the wind, we adopted wind directions for the months when the remote sensing images in May 2018 were taken. We calculated the wind frequency and added weights to the FAI. The equation is as follows:

$$
\lambda_{f}=\sum_{n=1}^{16} \lambda_{f(\theta)} \times P_{\theta}
$$

where $P_{\theta}$ represents the wind frequency in the $\theta$ direction. This study adopted the 16 compass orientation method. The FAI calculation methods could be divided into grid and vector algorithms according to the data used.

In this study, calculations of the 2D/3D urban morphology indexes were conducted using the ArcGIS Desktop platform.

\subsubsection{Scale analysis}

A straightforward scaling analysis was conducted by changing the grid size to quantify the individual explanatory powers of BCR, BVD, and FAI as well as their collective explanatory power to LST. Considering that the spatial resolution of LST was $100 \mathrm{~m}$, we selected $100 \mathrm{~m}, 200 \mathrm{~m}, 300$ $\mathrm{m}, 500 \mathrm{~m}, 700 \mathrm{~m}$, and $1000 \mathrm{~m}$, which could be divisible by the pixel size of LST, for the different grid sizes. For each grid cell, we calculated the mean LST as the indicator of LST. Then, we used the spatial overlay and spatial statistics tool in ArcGIS 10.2 to acquire indicator information for different grid sizes, and correlation and regression analyses between the urban morphology indexes and LST were constructed. The 2D/3D urban morphology indexes maps for different grid sizes can be found in Appendix(Figure A1, Figure A2 and Figure A3).

\subsubsection{Statistical analyses}

(1) Correlation analysis

The 2D/3D urban morphology has a complex relationship with LST; thus, it is more appropriate to use a nonlinear correlation coefficient than a linear correlation coefficient (e.g., the Pearson correlation coefficient). This study used the MIC (Reshef et al. 2011) to characterize the correlation. The MIC can be used to find not only linear relationships but also nonlinear relationships between 
variables; additionally, it can detect both functional relationships and non-function relationships (e.g., the superposition of functional relationships). The equation is as follows:

$$
M I C[x ; y]=\max _{|a||b|<B} \frac{I[a ; b]}{\log _{2}(\min (|a|,|b|))}
$$

where MIC $[x ; y]$ is the maximum information coefficient, $X$ represents the values of FAI, BCR and BVD, $\mathrm{y}$ is the surface temperature value, $a$ and $b$ are the number of grids divided into intervals in the $X$ and $Y$ directions, respectively, and $B$ is a variable expressed as the 0.6 power of the data volume.

The nonlinear correlation coefficients between the urban morphology indexes (BCR, BVD, FAI) and the LST under different grid sizes were calculated in Python 3.6 software. Subsequently, the fitting curve of LST and urban morphology indexes was drawn, and the quadratic model with a better fitting effect was selected as the final fitting curve.

(2) Geographically weighted regression

As a natural process, LST usually shows high spatial heterogeneity. Several studies have demonstrated that the GWR model is an effective method to detect spatial nonstationarity with better performance (Zhao et al. 2018). To detect whether there was spatial autocorrelation among the LST, BCR, BVD, and FAI, Moran's I model was separately constructed. Moran's I increased with increasing scale and was greater than 0.56, which indicated that the LST, BCR, BVD, and FAI had significant positive spatial correlations. Therefore, this study utilized GWR to further quantify the explanatory power of urban morphology on LST. GWR is an extension of the conventional regression framework, and it allows the model parameters to vary in space. Hence, it breaks through the unrealistic hypothesis supported by conventional models in geoscience that the association between dependent and independent variables is constant over space. Specifically, GWR models the associations through the following (Wheeler \&Páez 2010):

$$
Y_{\mathrm{k}}=\beta_{0}\left(\mathrm{u}_{\mathrm{i}}, v_{i}\right)+\sum_{i=1}^{k} \beta_{i}\left(\mathrm{u}_{\mathrm{i}}, v_{i}\right) X_{i}+\varepsilon_{k}
$$

where $\left(u_{i}, v_{i}\right)$ denotes the spatial coordinates of point $i, X_{i k}$ is the $k$ th indicator at observation $\mathrm{i}$ (i.e., BCR, BVD, and FAI), $\varepsilon_{k}$ is a random error term, $\beta_{0}\left(u_{i}, v_{i}\right)$ is the intercept value and $\beta_{i}\left(u_{i}, v_{i}\right)$ represents the coefficient at point $i$, which is estimated as follows:

$$
W_{\mathrm{ij}}=\exp \left(-\left(\frac{\mathrm{d}_{\mathrm{ij}}}{\mathrm{b}}\right)^{2}\right)
$$

where $W_{i j}$ is the weight influence between grids $i$ and $j, D_{i j}$ is the Euclidean distance between grids $i$ and $j$, and $b$ is the band width.

\section{Results}

\subsection{Statistical features of LST, BCR, BVD, and FAI under different grid sizes}

The thresholds and spatial patterns of LST, BCR, BVD, and FAI changed with different grid sizes. When the grid size was $100 \mathrm{~m}$, the local details were the most obvious. In addition, with the increase in grid size, the LST, BCR, BVD, and FAI all presented extreme values, the mean values decreased, and the degree of data dispersion was reduced (Figure 4), showing that LST, BCR, BVD, and FAI were scale dependent and sensitive to scale changes. The coarse scale had a generalization effect, and the fine scale had a detailed amplification effect, which conformed to the spatial autocorrelation law. The larger the scale range is, the more it can reflect the global trend, the smaller 
the scale is, the more local changes can be reflected, and the more representative it is of the local area.
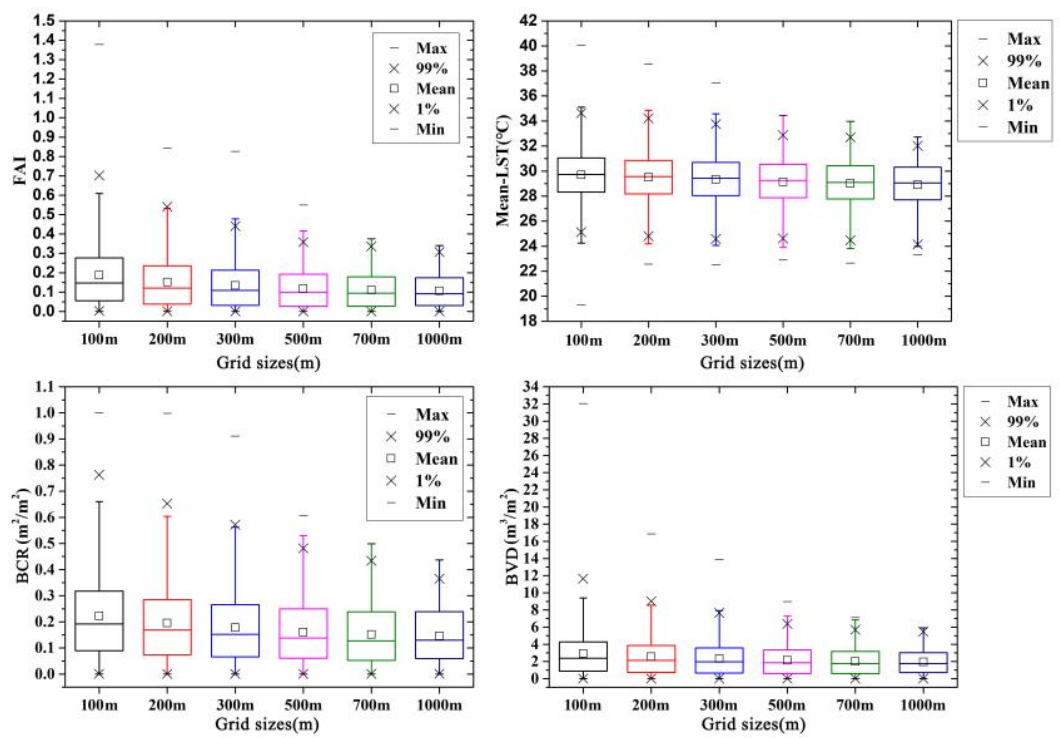

Fig. 4 Box plot of LST and UMI distribution under different grid sizes

\subsection{Correlations among BCR, BVD, FAI and LST under different grid sizes}

Table 1 shows the results of the correlation analysis for LST and 2D/3D urban morphology. Our results showed that LST was only weakly correlated with BVD and FAI (0.081-0.036 and 0.0870.355 , respectively) but was moderately correlated with BCR (0.157-0.517), which indicated that the BCR had the most significant and positive effect on LST, while the BVD and FAI likely had relatively smaller impacts on LST. The strongest to weakest sequence of the correlation coefficient at the 100-m grid size was BCR $>$ FAI $>$ BVD, while the sequence was BCR $>$ BVD $>$ FAI at the 2001000 -m grid size. It was notable that the individual urban morphology and LST had stronger positive correlations as grid size increased. When the grid scale was $1000 \mathrm{~m}$, the correlation coefficient between LST and FAI, BCR, and BVD was the largest.

Table 1 Maximum information coefficient between UMI and LST under different scales

\begin{tabular}{cccc}
\hline Grid sizes & BCR & BVD & FAI \\
\hline $100 \mathrm{~m}$ & $0.157^{* *}$ & $0.081^{* *}$ & $0.087^{* *}$ \\
$200 \mathrm{~m}$ & $0.232^{* *}$ & $0.118^{* *}$ & $0.116^{* *}$ \\
$300 \mathrm{~m}$ & $0.308^{* *}$ & $0.179^{* *}$ & $0.165^{* *}$ \\
$500 \mathrm{~m}$ & $0.388^{* *}$ & $0.276^{* *}$ & $0.245^{* *}$ \\
$700 \mathrm{~m}$ & $0.492^{* *}$ & $0.364^{* *}$ & $0.323^{* *}$ \\
$1000 \mathrm{~m}$ & $0.517^{* *}$ & $0.368^{* *}$ & $0.355^{* *}$ \\
\hline
\end{tabular}

note: $* *$ means passing $1 \%$ significance test

Interestingly, Figure 5 shows that the relationship between LST and individual urban morphology exhibited an inverted U-shaped nonlinear relationship of the environmental Kuznets curve, implying that BCR, BVD, and FAI played a positive role in LST at a certain level; furthermore, when they exceed a critical value, they will inhibit LST. Additionally, as the grid size increased, the quadratic function showed a better fitting effect, which was confirmed by the higher $\mathrm{R}^{2}$. Further analysis showed that the inflection point values of the fitting curve exhibited an overall slight decreasing trend with increasing grid size (Figure 6), indicating that a scaling effect existed in the influence characteristics and mechanisms of 2D/3D urban morphology on LST. 

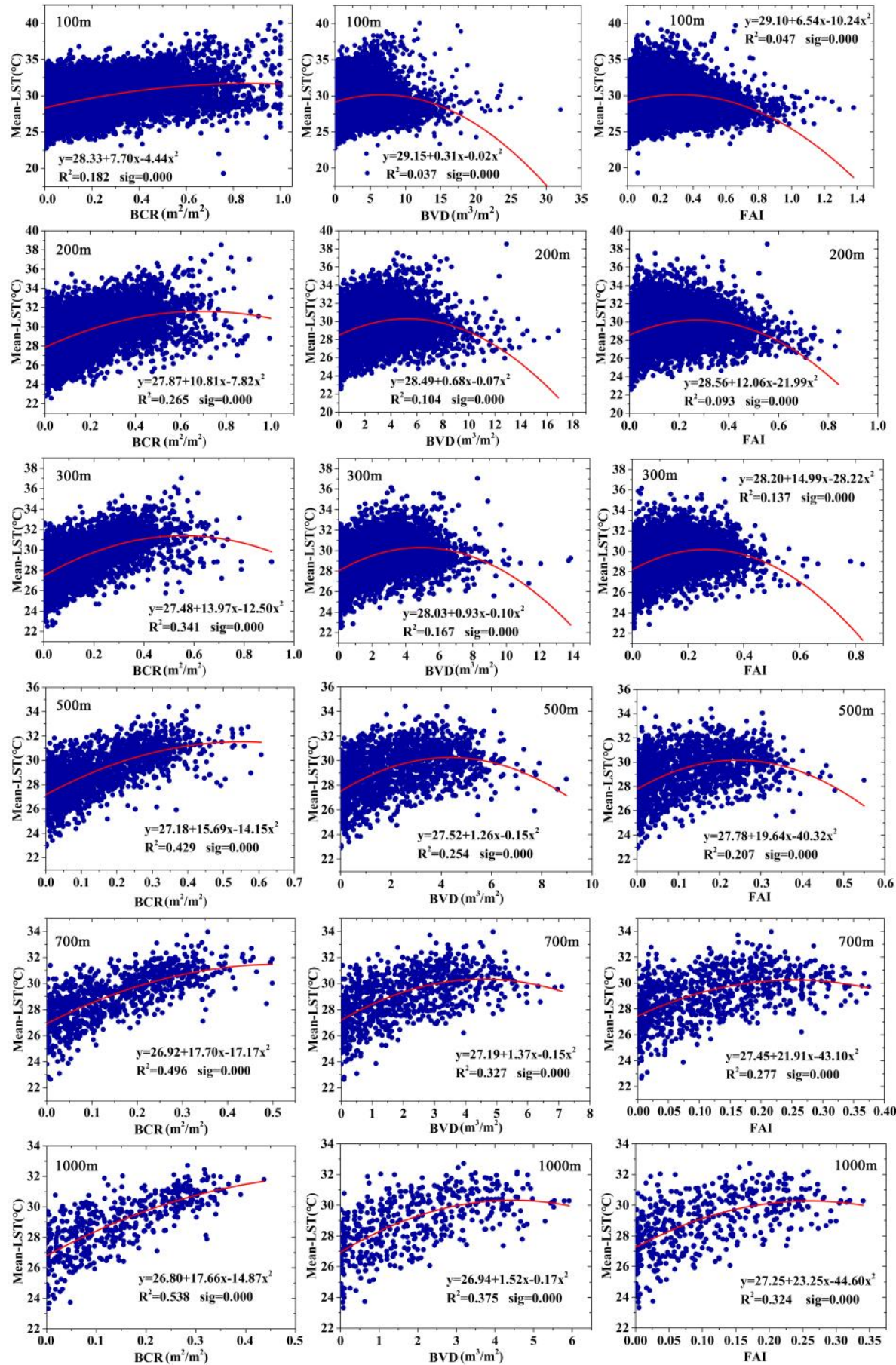

Fig. 5 The scatterplots of LST in 2018 and 2D/3D urban morphology.
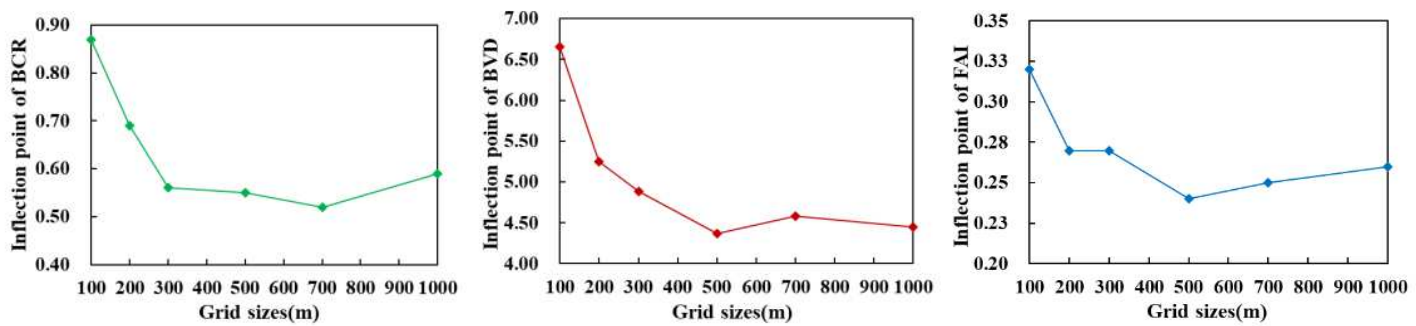
Grid sizes(m) Grid sizes(m)

Grid sizes(m)

Fig. 6 Inflection point of fitting curve between 2D/3D urban morphology and LST 


\subsection{Regression among BCR, BVD, FAI and LST under different grid sizes}

Table 2 lists the outcome of the GWR. The results showed that the goodness-of-fit $\left(\mathrm{R}^{2}\right)$ was between 0.505 and 0.734 , and these values were all greater than 0.50 across the different grid sizes, indicating that approximately $50.50 \%-73.40 \%$ of the variation in LST could be explained by the urban morphology indexes selected in this study. Moreover, as the grid sizes increased, $\mathrm{R}^{2}$ presented an increasing trend between the $100 \mathrm{~m}$ and $700 \mathrm{~m}$ grid sizes, with a maximum of 0.752 for the 700 $\mathrm{m}$ grid size; however, the value decreased when the grid size ranged between $700 \mathrm{~m}$ and $1000 \mathrm{~m}$.

In addition, from the perspective of regression coefficients, BCR was the dominant positive contributor to LST, which was confirmed by the relatively higher regression coefficient $(0.228$ 0.574 ) than that for the BVD and FAI, and its relative influence reached a maximum at the 1000-m scale. BVD had a combination of positive and negative weak contributions to the variation in LST; for example, it had a negative impact on LST when the grid size ranged between $100 \mathrm{~m}$ and $200 \mathrm{~m}$ but a positive impact when the grid size ranged between $300 \mathrm{~m}$ and $1000 \mathrm{~m}$. Finally, it had the strongest positive impact on LST at the 500-m grid size. Specifically, the LST decreased with the increasing BVD until it reached a threshold at the 300-m grid size. In contrast, the FAI showed a negative contribution to the variation in LST; specifically, its negative impact on LST exerted a generally decreasing trend at grid sizes between $100 \mathrm{~m}$ and $300 \mathrm{~m}$ and reached a maximum negative value at the 500-m grid size. Beyond the scale of $500 \mathrm{~m}$, the negative impact decreased.

Table 2 Results of GWR model between 2D/3D urban morphology and LST

\begin{tabular}{cccccc}
\hline $\begin{array}{c}\text { Grid } \\
\text { sizes }(\mathrm{m})\end{array}$ & AICc & $\mathrm{R}^{2}$ & $\begin{array}{c}\text { Coefficient } \\
\text { of BCR }\end{array}$ & $\begin{array}{c}\text { Coefficient } \\
\text { of BVD }\end{array}$ & $\begin{array}{c}\text { Coefficient } \\
\text { of FAI }\end{array}$ \\
\hline $100 \mathrm{~m}$ & -54729.399 & 0.505 & 0.228 & -0.051 & -0.100 \\
$200 \mathrm{~m}$ & -18602.914 & 0.541 & 0.392 & -0.011 & -0.078 \\
$300 \mathrm{~m}$ & -8848.707 & 0.595 & 0.467 & 0.027 & -0.083 \\
$500 \mathrm{~m}$ & -3211.341 & 0.693 & 0.468 & 0.183 & -0.201 \\
$700 \mathrm{~m}$ & -1862.860 & 0.752 & 0.448 & 0.170 & -0.141 \\
$1000 \mathrm{~m}$ & -767.682 & 0.734 & 0.574 & 0.108 & -0.103 \\
\hline
\end{tabular}

The results shown in Table 3 clearly illustrate the proportion of grids that had positive and negative effects of urban morphology indexes on LST at different scales. In the grid size range of 100-300 m, the positive effect proportion was as follows: BCR $>$ FAI $>$ BVD, while in the grid size range of 500-1000 m, the strong-to-weak sequence of the positive effect ranking was as follows BCR > BVD > FAI. Among these, BCR had the largest positive effect on LST, and all grids showed a positive correlation effect at the 1000-m grid size. Additionally, the positive effect of the FAI on LST at the fine scale was higher than that at the coarse scale, and the positive effects of BCR and BVD at the coarse scale were higher than those at the fine scale, which indicated that with the increase in scale, some variation characteristics in the micro-scale were gradually diluted, and the influence of dominant factors on surface temperature was gradually strengthened.

Table 3 Ratio of positive and negative effects of 2D/3D urban morphology on LST

\begin{tabular}{ccccccc}
\hline \multirow{2}{*}{ Grid sizes(m) } & \multicolumn{2}{c}{ BCR } & \multicolumn{2}{c}{ BVD } & \multicolumn{2}{c}{ FAI } \\
\cline { 2 - 6 } & $\begin{array}{c}\text { Positive } \\
\text { effect }(\%)\end{array}$ & $\begin{array}{c}\text { Negative } \\
\text { effect }(\%)\end{array}$ & $\begin{array}{c}\text { Positive } \\
\text { effect( } \%)\end{array}$ & $\begin{array}{c}\text { Negative } \\
\text { effect }(\%)\end{array}$ & $\begin{array}{c}\text { Positive } \\
\text { effect(\%) }\end{array}$ & $\begin{array}{c}\text { Negative } \\
\text { effect }(\%)\end{array}$ \\
\hline $100 \mathrm{~m}$ & 1.89 & 98.11 & 62.16 & 37.84 & 65.75 & 34.25 \\
$200 \mathrm{~m}$ & 1.72 & 98.28 & 56.88 & 43.12 & 64.72 & 35.28 \\
$300 \mathrm{~m}$ & 0.95 & 99.05 & 56.53 & 43.47 & 56.99 & 43.01 \\
$500 \mathrm{~m}$ & 1.30 & 98.70 & 69.37 & 30.63 & 27.73 & 72.27 \\
$700 \mathrm{~m}$ & 1.44 & 98.56 & 66.52 & 33.48 & 25.50 & 74.50 \\
\hline
\end{tabular}


Figure 7 displays the spatial distribution of $\mathrm{R}^{2}$ and the individual urban morphology coefficient. The $\mathrm{R}^{2}$ formed a "multicore" distribution structure with the central urban area and the eastern new town as the core area, and it gradually extended to the periphery. From the spatial distribution of the regression coefficient, the positive influence area of the FAI presented a strip pattern from the centre to the southwest, the low negative impact area was distributed in the northeast corner of Jinan city, the area positively influenced by the BCR was mainly distributed in the central city and the eastern new city, and the area negatively influenced was mainly distributed in the peripheral area. Additionally, the areas positively influenced by BVD were scattered and most areas were concentrated in the northeast of the study area. In contrast, the centre of the study area became an area concentrated with negative impacts. Therefore, spatial heterogeneity existed regarding the effects of 2D and 3D urban morphology.
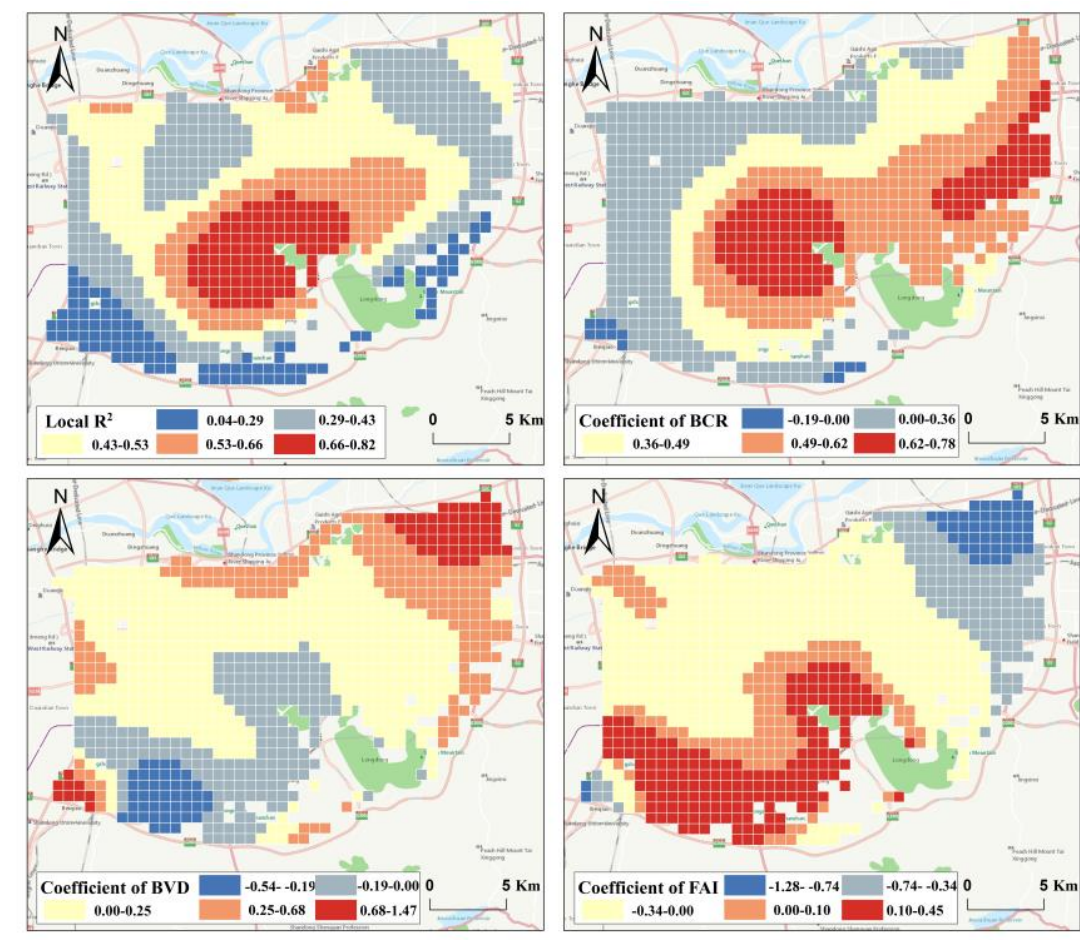

Fig. 7 Schematic diagram of local R2 and regression coefficients of the GWR for urban morphology and LST

\section{Discussion}

\subsection{Effect characteristics of 2D/3D urban morphology on LST}

There are many potential drivers of LST, and the mechanism is complex. The geographical environment and natural base are the background of the urban internal thermal environment. The factors influencing the surface temperature at the micro-scale are more complex. Urban underlying surface properties, vegetation coverage, anthropologic heat, wind speed, wind direction, cloud coverage, rainfall, local air humidity and other meteorological conditions will have certain impacts on LST (Elmes et al. 2017, Han et al. 2017, Sadiq Khan et al. 2020, Subedi \&Fullen 2009, Wenhui et al. 2017). This study investigated the effects of 2D/3D urban morphology on LST across various grid sizes. The correlation analyses revealed that BCR, BVD, and FAI had a positive correlation with the variation in LST at various grid sizes. Generally, LST was only weakly correlated with 
BVD and FAI but was moderately correlated with BCR, as shown in Table 1. The results of the GWR analyses also indicated a significant positive impact on LST variation, which was consistent with what was found in the correlation analysis results. In particular, it the effect of BVD on LST changed from negative to positive at the $300-\mathrm{m}$ grid size, and the FAI exerted a negative contribution to LST variation, which was inconsistent with the related analysis results. This result suggested that although BCR, BVD, and FAI were positively correlated with LST, BCR played the most important role in terms of affecting LST variation, and the largest proportion of LST was accounted for by BCR. The BVD and FAI made relatively limited contributions to the LST variation compared with the BCR. Additionally, the effects of 2D/3D urban morphology on LST variation exhibited significant spatial heterogeneity, as shown in Figure 7.

Interestingly, there was an inverted U-shaped curve relationship between 2D/3D urban morphology and LST, especially for the BVD and FAI (Figure 5); in other words, the BCR, BVD, and FAI had a positive effect on LST at a certain level, and when they reached a critical value, they began to inhibit the increase in LST, and the critical value changed with the change in scale, which was sensitive to the change in grid size. This result has rarely been found in other studies, and most studies reported a positive linear correlation between LST and urban morphology indexes (B et al., Hu et al. 2020, Huang \&Wang 2019b, Kammuang-Lue et al. 2015), which may cover up some important mechanisms. The inverted U-shaped curve relationship between 2D/3D urban morphology and LST variation implies that the impact of 2D/3D urban morphology on LST is complex and contradictory. On the one hand, a higher BCR means an increase in high-density buildings with impervious surfaces as the primary source, and these surfaces tend to have lower albedos and absorb more solar irradiation (Jamei \&Rajagopalan 2017). The higher BVD and FAI denote the distribution of high-volume density buildings, which alter the thermal properties of the surface while obstructing urban ventilation. The FAI measures the ventilation effect of a building in 16 directions; a higher FAI value indicates worsened ventilation conditions. Additionally, the regions with high BCR, BVD and FAI are more likely to have a larger population as well as a larger number of man-made heat emissions caused by air-conditioning heat production and traffic problems than areas with smaller populations. On the other hand, when they exceed a certain threshold, buildings block each other, and the SVF changes, resulting in a building shading effect. High-rise and high-density buildings may cast more shadows, which can produce a significant cooling effect by shielding solar radiation; they also enhance the surface roughness to generate mechanical turbulence, thereby promoting convective heat dissipation (Perini \&Magliocco 2014). It is generally found that the ground temperature of high-rise dense high-rise buildings and open high-rise buildings is lower than that of low-rise dense middle-rise buildings, and the temperature difference of the building is above $50^{\circ} \mathrm{C}$, which can reach $49.5^{\circ} \mathrm{C}$ (Chen et al. 2017, Koc et al. 2018).

\subsection{Scale effects of 2D/3D urban morphology on LST}

Compared with previous research exploring the effects of urban morphology on LST at a singular scale (Hu et al. 2020, Yao et al. 2020), our results demonstrated that there was a significant scale effect in the individual index and the relationship between 2D/3D urban morphology and LST variation. For the individual index, the statistical features of LST, BCR, BVD, and FAI changed with the variation in grid size. Specifically, with the increase in grid size, the LST, BCR, BVD, and FAI all presented extreme values, the man values declined, the degree of data dispersion was reduced, and the global character was enhanced. In addition, the correlation coefficients of BCR, BVD, FAI and LST increased with increasing spatial scale. However, it is important to note that there was an 
obvious "inflection point" in the strong-to-weak sequence of the correlation coefficient at $200 \mathrm{~m}$, changing from "BCR $>$ FAI $>$ BVD" to "BCR $>$ BVD $>$ FAI". A possible explanation might be that the FAI tends to show a relatively important effect on LST variation at a finer scale compared with the effect of BVD.

Our finding on inflection points of the fitting curve between 2D/3D urban morphology and LST indicated that the inflection point of the effect of 2D/3D urban morphology on LST was sensitive to scale. With increasing grid size, the inflection point displayed a general downward trend, indicating that the conversion threshold of positive and negative impacts of $2 \mathrm{D} / 3 \mathrm{D}$ urban morphology on LST was significantly influenced by the spatial scale. The results of GWR demonstrated that the explanation rate of 2D/3D urban morphology on LST exhibited a general increasing trend at the $100-700-\mathrm{m}$ scale and showed a maximum value $(75.2 \%)$ at the $700-\mathrm{m}$ scale; however, it decreased at the 1000-m scale, as shown in Table 2. This finding is directly in line with previous studies (Xu et al. 2017); however, others have shown that the correlation between urban morphology indexes and LST decreases with increasing scale (Yang et al. 2019b). A possible explanation for this difference might be that the results from different cities may obtain diverse results, which are closely related to the shape, height and building combination mode of buildings in cities, and the urban texture and crown characteristics of different regions are diverse. It is worth discussing these interesting facts revealed by the proportion of grids with positive and negative effects of BCR, BVD and FAI on LST at different scales. As the scale increased, the FAI exerted a stronger negative effect on LST, while the BCR and BVD had stronger positive effects on LST.

Due to the spatial heterogeneity and scale sensitivity of the influence degree of urban morphology indexes on LST, the spatial difference and scale selection of different index influence degrees can be considered when formulating urban thermal environment governance countermeasures according to urban building parameters to make decisions more targeted.

\subsection{Limitations and recommendations for future studies}

Due to the limitation of the data, this study obtained instantaneous surface temperature products at the time of satellite transit. In the future, we can try to use the model to simulate continuous surface temperature data within a day. Moreover, the obtained building data included only the outline, floor and type of building. The height of the building was calculated by the floor and average floor height, which makes the height of the building possible. The deviation in the actual height of the building has an uncertain impact on the 2D/3D urban morphology. The surface temperature of each grid in this study was a simple average temperature, which makes it difficult to fully reflect the surface temperature characteristics within the grid; thus, a better average temperature calculation method should be developed in the future. In addition, the factors affecting LST are more complex, such as terrain, background climate, vegetation, and water distribution. The distance from vegetation and water bodies and the different types, uses, materials and combination modes of urban buildings will also have direct impacts on the surface temperature. The above factors should be considered in future research. In addition, the influence of grid scale on the relationship between urban building parameters and LST needs further study and discussion.

\section{Conclusions}

2D/3D urban morphological information has critical impacts on LST. To enhance our understanding of the effects of 2D/3D urban morphology on LST, this study established a multiscale analysis of the effects of 2D/3D urban morphology on LST in the central urban districts of Jinan 
city using the MIC and GWR methods. The BCR had a stronger association with LST variation than did BVD and FAI, and the relationship between the BCR, BVD, and FAI and the LST was an inverse U-shaped curve, implying that the BCR, BVD and FAI positively impacted LST at a certain level. When they exceeded a critical value, they began to inhibit LST, which is an important finding in the understanding of the effects of 2D/3D urban morphology on LST.

Another contribution of this study was our examination of how the influence of BCR, BVD, and FAI on LST changed with increasing spatial scale $(100 \mathrm{~m}-1000 \mathrm{~m})$. Our results suggest that there exists a significant scale effect in individual indexes and the relationship between 2D/3D urban morphology and LST variation. With the increase in grid size, there was a stronger correlation between BCR, BVD, and FAI and LST; the explanation rate of 2D/3D urban morphology to LST first increased and then decreased, with a maximum value (75.2\%) at the 700-m scale; the FAI exerted a stronger negative effect on LST; and the BCR and BVD had stronger positive effects on LST. These findings enhance our understanding of the effects of 2D/3D urban morphology on LST and provide insights into the treatment of thermal environmental problems at different scales.

Author Contribution The manuscript was reviewed and approved for publication by all authors. YL and BZ conceived and designed the experiments; YL, ZW and XL performed the experiments; YL, BZ, and ZW analyzed the data. YL and BZ wrote the paper. ZW and XL reviewed and revised the paper.

Funding This research was supported by the National Social Science Fund of China (No. 18BJY086).

Data and materials availability The availability of data and materials is on the base of personal request.

Acknowledgments We would like to thank the Editor and the anonymous reviewers for providing constructive comments and suggestions.

\section{Declarations}

Ethics approval and consent to participate The manuscript was reviewed and ethical approved for publication by all authors. The manuscript was reviewed and consents to participate by all authors.

Consent to publish The manuscript was reviewed and consents to publish by all authors

Competing interest The authors declare no conflict of interest.

Appendix A
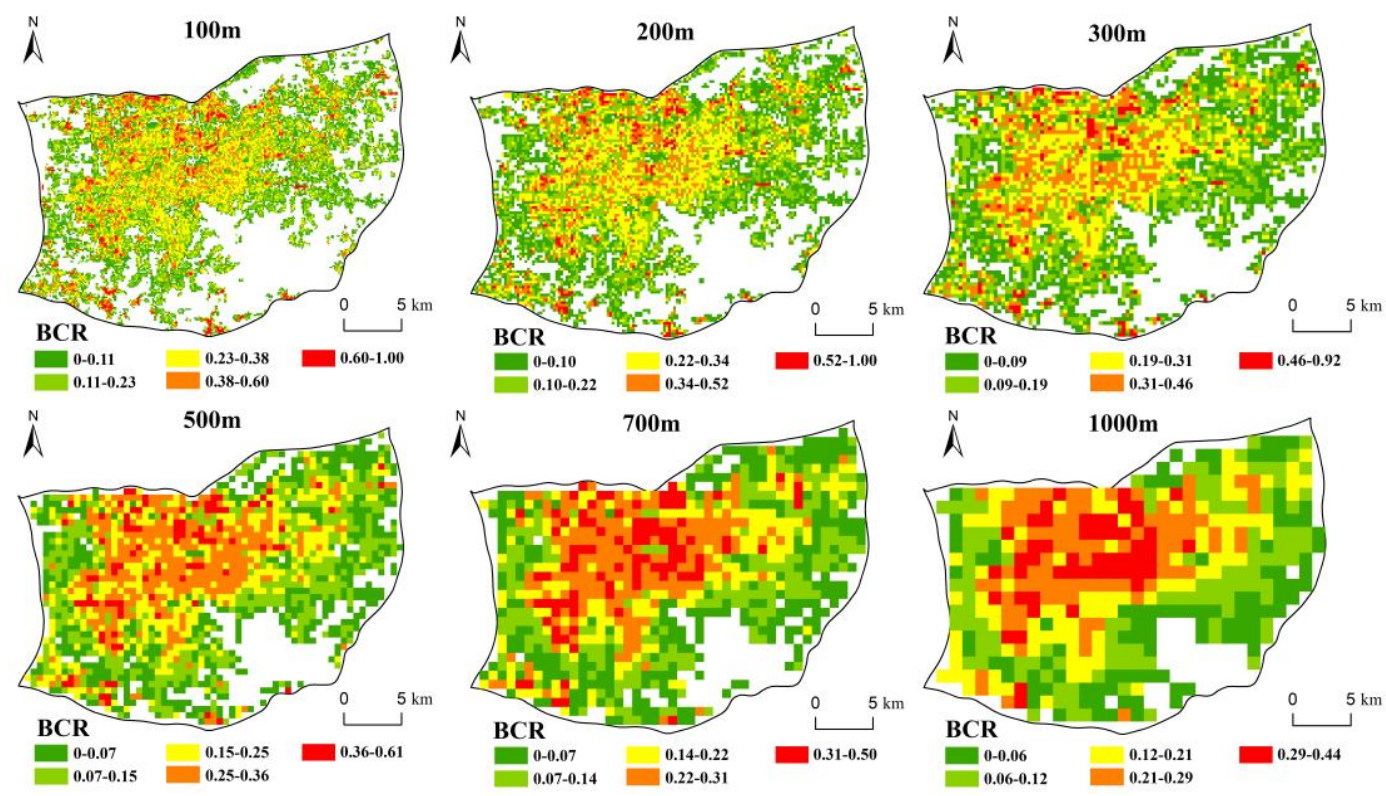

A

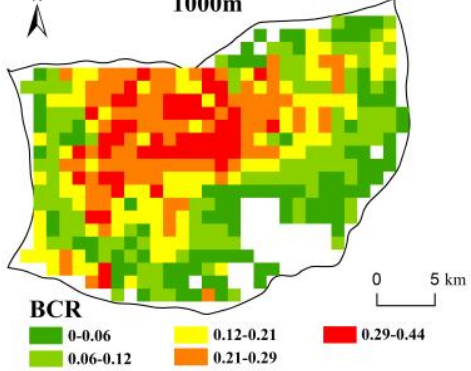


Figure A1. Map of BCR spatial distribution at different grid sizes.
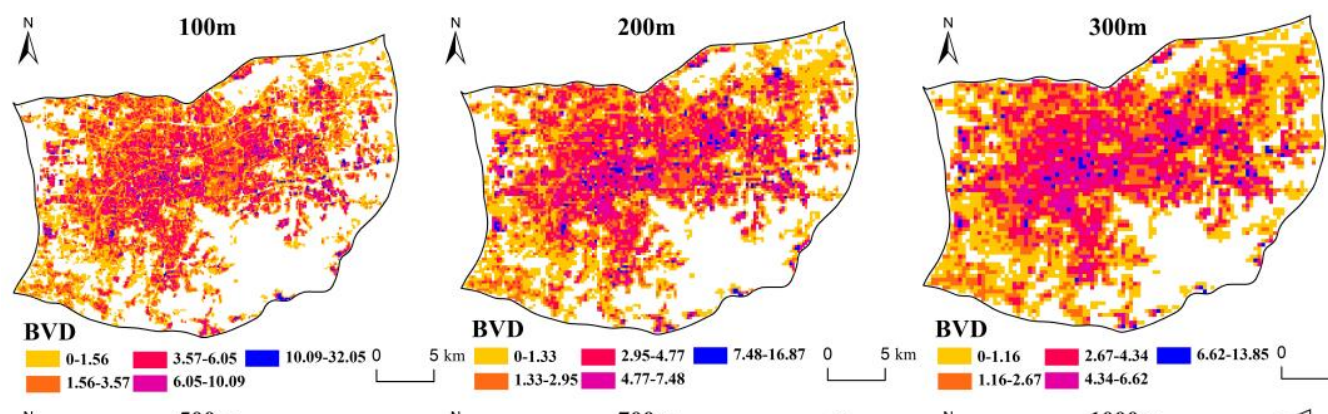

$0-1.16$
$-2.67-4.34$
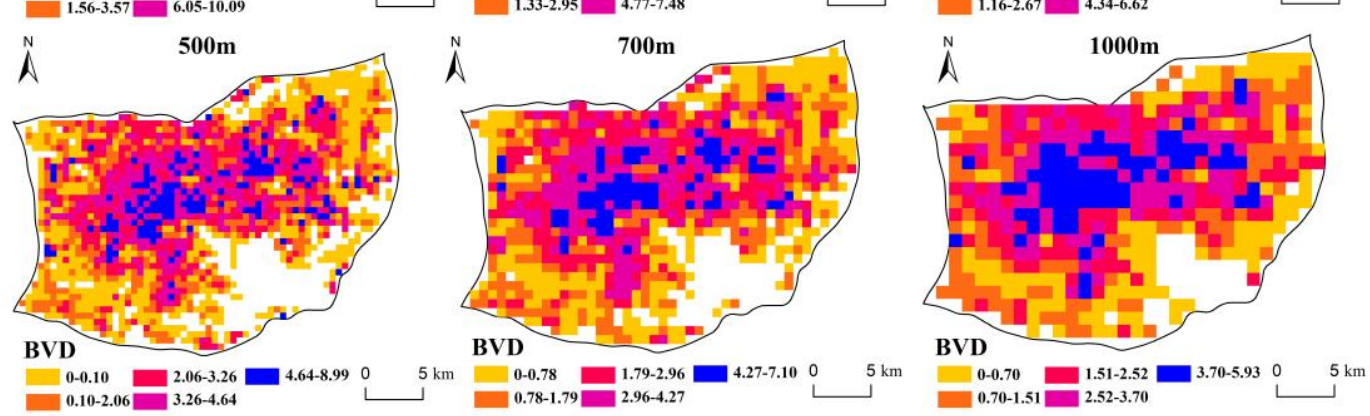

Figure A2. Map of BVD spatial distribution at different grid sizes.
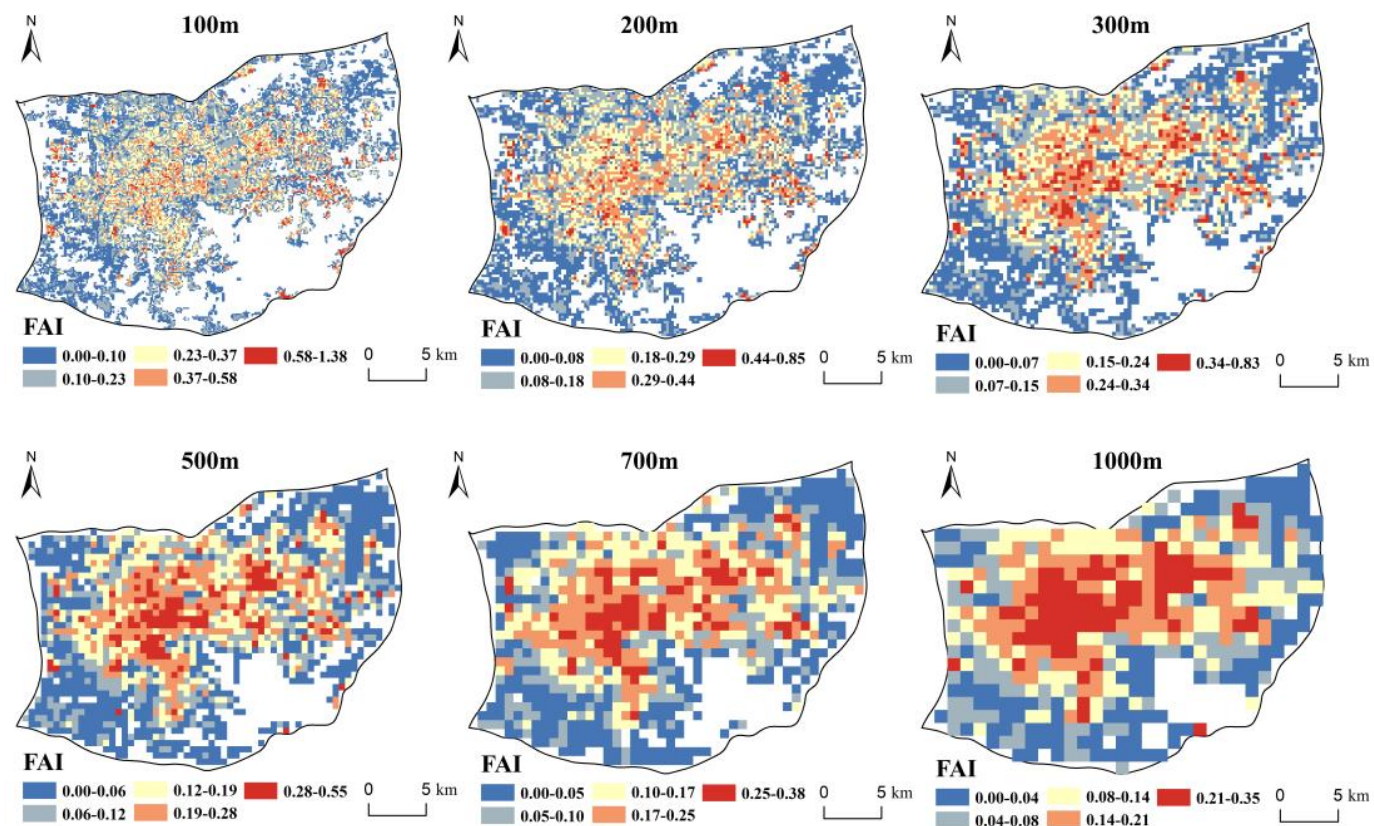

Figure A3. Map of FAI spatial distribution at different grid sizes.

\section{References}

B FSA, C ML, D YW, E HW, B YCA The effects of 3D architectural patterns on the urban surface temperature at a neighborhood scale: Relative contributions and marginal effects. Journal of Cleaner Production 258

Carmona PL, Tran DX, Pla F, Myint SW, Kieu HV (2017): Characterizing the relationship between land use land cover change and land surface temperature. ISPRS Journal of Photogrammetry and Remote Sensing 124, 119-132

Chen XL, Zhao HM, Li PX, Yin ZY (2006): Remote sensing image-based analysis of the relationship between urban heat island and land use/cover changes. Remote Sensing of Environment 104, 
$133-146$

Chen YC, Lin TP, Shih WY (2017): Modeling the urban thermal environment distributions in Taipei Basin using Local Climate Zone (LCZ), Urban Remote Sensing Event

Coseo P, Larsen L (2019): Accurate Characterization of Land Cover in Urban Environments: Determining the Importance of Including Obscured Impervious Surfaces in Urban Heat Island Models. Atmosphere 10

Elmes, Arthur, Rogan, John, Williams, Christopher, Ratick, Samuel, Nowak, David (2017): Effects of urban tree canopy loss on land surface temperature magnitude and timing. ISPRS Journal of Photogrammetry \& Remote Sensing

Giridharan R, Lau SSY, Ganesan S, Givoni B (2007): Urban design factors influencing heat island intensity in high-rise high-density environments of Hong Kong. Building \& Environment 42, 3669-3684

Grimm NB, Faeth SH, Golubiewski NE, Redman CL, Wu J, Bai X, Briggs JM (2008): Global Change and the Ecology of Cities. Science 319, 756

Han SR, Wei S, Zhou W, Zhang MJ, Xu C (2017): Quantifying the spatial pattern of urban thermal fields based on point of interest data and Landsat images. Acta Ecologica Sinica

Hu Y, Dai Z, Guldmann JM (2020): Modeling the impact of 2D/3D urban indicators on the urban heat island over different seasons: A boosted regression tree approach. Journal of Environmental Management 266, 110424

Huang X, Wang Y (2019a): Investigating the effects of 3D urban morphology on the surface urban heat island effect in urban functional zones by using high-resolution remote sensing data: A case study of Wuhan, Central China. Isprs Journal of Photogrammetry and Remote Sensing 152, 119131

Huang X, Wang Y (2019b): Investigating the effects of 3D urban morphology on the surface urban heat island effect in urban functional zones by using high-resolution remote sensing data: A case study of Wuhan, Central China. Isprs Journal of Photogrammetry \& Remote Sensing 152, 119131

Inouye DW (2015): The next century of ecology. Science 349, 565

Ivajnsic D, Kaligaric M, Ziberna I (2014): Geographically weighted regression of the urban heat island of a small city. Applied Geography 53, 341-353

Jamei E, Rajagopalan P (2017): Urban development and pedestrian thermal comfort in Melbourne. Solar Energy 144, 681-698

Kammuang-Lue N, Sakulchangsatjatai P, Sangnum P, Terdtoon P (2015): Influences of population, building, and traffic densities on urban heat island intensity in Chiang Mai City, Thailand. Thermal Science 19, 85-85

Koc CB, Osmond P, Peters A, Irger M (2018): Understanding Land Surface Temperature Differences of Local Climate Zones Based on Airborne Remote Sensing Data. Selected Topics in Applied Earth Observations and Remote Sensing, IEEE Journal of 11, 2724-2730

Kolokotroni M, Zhang Y, Watkins R (2007): The London Heat Island and building cooling design. Solar Energy 81, 102-110

Levin, Simon, A. (1992): The problem of pattern and scale in ecology. Ecology

Liu Y, Li Q, Yang L, Mu K, Zhang M, Liu J (2020): Urban heat island effects of various urban morphologies under regional climate conditions. Science of the Total Environment 743

Luxmoore DA, Jayasinghe MTR, Mahendran M (2005): Mitigating temperature increases in high lot 
density sub-tropical residential developments. Energy \& Buildings 37, 1212-1224

Perini K, Magliocco A (2014): Effects of vegetation, urban density, building height, and atmospheric conditions on local temperatures and thermal comfort. Urban Forestry \& Urban Greening 13, 495-506

Petralli M, Massetti L, Brandani G, Orlandini S (2014): Urban planning indicators: Useful tools to measure the effect of urbanization and vegetation on summer air temperatures. International Journal of Climatology 34

Reshef DN, Reshef YA, Finucane HK, Grossman SR, McVean G, Turnbaugh PJ, Lander ES, Mitzenmacher M, Sabeti PC (2011): Detecting novel associations in large data sets. science 334, 1518-1524

Sadiq Khan M, Ullah S, Sun T, Rehman AUR, Chen L (2020): Land-Use/Land-Cover Changes and Its Contribution to Urban Heat Island: A Case Study of Islamabad, Pakistan. Sustainability 12

Seto KC, Gueneralp B, Hutyra LR (2012): Global forecasts of urban expansion to 2030 and direct impacts on biodiversity and carbon pools. Proceedings of the National Academy of Sciences of the United States of America 109, 16083-16088

Stefania B, Chaiyapon K (2018): Land Surface Temperature and Urban Density: Multiyear Modeling and Relationship Analysis Using MODIS and Landsat Data. Remote Sensing 10, 1471

Subedi M, Fullen MA (2009): Temporal changes in soil temperature at the Hilton Experimental Site, Shropshire, UK (1982-2006): Evidence of a warming trend? Archives of Agronomy and Soil Science 55

Taha H (1997): Urban climates and heat islands: albedo, evapotranspiration, and anthropogenic heat. 25, 99-103

Tiatragul S, Kurniawan A, Kolbe JJ, Warner DA (2017): Embryos of non-native anoles are robust to urban thermal environments. J Therm Biol 65, 119-124

Tu L, Qin Z, Li W, Geng J, Yang L, Zhao S, Zhan W, Wang F (2016): Surface urban heat island effect and its relationship with urban expansion in Nanjing, China. Journal of Applied Remote Sensing 10,026037

Voogt JA, Oke TR (2003): Thermal remote sensing of urban climates. Remote Sensing of Environment $86,370-384$

Wang F, Qin Z, Song C, Tu L, Karnieli A, Zhao S (2015): An Improved Mono-Window Algorithm for Land Surface Temperature Retrieval from Landsat 8 Thermal Infrared Sensor Data. Remote Sensing 7, 4268-4289

Wang J, Qingming Z, Guo H, Jin Z (2016): Characterizing the spatial dynamics of land surface temperature-impervious surface fraction relationship. International Journal of Applied Earth Observation and Geoinformation 45, 55-65

Wang X, Zhou T, Tao F, Zang F (2019): Correlation Analysis between UBD and LST in Hefei, China, Using Luojia1-01 Night-Time Light Imagery. Applied Sciences 9

Wang Y, Xu M, Li J, Jiang N, Wang D, Yao L, Xu Y (2020): The Gradient Effect on the Relationship between the Underlying Factor and Land Surface Temperature in Large Urbanized Region. Land 10

Weng Q (2009): Thermal infrared remote sensing for urban climate and environmental studies: Methods, applications, and trends. ISPRS Journal of Photogrammetry and Remote Sensing 64, 335-344

Wenhui K, Tianrong Y, Ailin L, Chi Z, Dengsheng LU, Wenfeng C (2017): An EcoCity model for regulating urban land cover structure and thermal environment: Taking Beijing as an example. 
Science China Earth Sciences 60, 1098-1109

Wheeler DC, Páez A (2010): Geographically Weighted Regression. Springer Berlin Heidelberg

Wong MS, Nichol J, Lee KH (2010): A Satellite View of Urban Heat Island: Causative Factors and Scenario Analysis. Korean Journal of Remote Sensing 26

Wu J (2004): Effects of Changing Scale on Landscape Pattern Analysis: Scaling Relations. Landscape Ecology 19, 125-138

Xu Y, Ren C, Ma PF, Ho J, Wang WW, Lau KKL, Lin H, Ng E (2017): Urban morphology detection and computation for urban climate research. Landscape and Urban Planning 167, 212-224

Yang F, Lau SSY, Qian F (2010): Summertime heat island intensities in three high-rise housing quarters in inner-city Shanghai China: Building layout, density and greenery. Building \& Environment $45,115-134$

Yang J, Wang Y, Xiao X, Jin C, Xia J, Li X (2019a): Spatial differentiation of urban wind and thermal environment in different grid sizes. Urban Climate 28

Yang J, Wang YC, Xiao XM, Jin C, Xia JH, Li XM (2019b): Spatial differentiation of urban wind and thermal environment in different grid sizes. Urban Climate 28, 13

Yang SJ, Ran GP, Zhang W, Wang ZH (2020): THE COOLING EFFECT OF AN URBAN LAKE LANDSCAPE ON THE URBAN HEAT ISLAND: A CASE STUDY IN JINAN, CHINA. Applied Ecology and Environmental Research 18, 2197-2211

Yao L, Xu Y, Zhang B (2019): Effect of urban function and landscape structure on the urban heat island phenomenon in Beijing, China. Landscape and Ecological Engineering 15

Yao L, Li T, Xu M, Xu Y (2020): How the landscape features of urban green space impact seasonal land surface temperatures at a city-block-scale: An urban heat island study in Beijing, China. Urban Forestry \& Urban Greening 52, 126704

Youpei, Hu, Marcus, White, Wowo, Ding (2016): An Urban Form Experiment on Urban Heat Island Effect in High Density Area. Procedia Engineering

Yu B, Liu H, Wu J, Hu Y, Zhang L (2010): Automated derivation of urban building density information using airborne LiDAR data and object-based method. Landscape \& Urban Planning 98, 210219

Yu ZW, Yao Y, Yang G, Wang X, Vejre H (2019): Strong contribution of rapid urbanization and urban agglomeration development to regional thermal environment dynamics and evolution. Forest Ecology and Management 446, 214-225

Zhao C, Jensen J, Weng Q, Weaver R (2018): A Geographically Weighted Regression Analysis of the Underlying Factors Related to the Surface Urban Heat Island Phenomenon. Remote Sensing 10

Zhou W, Wang J, Cadenasso ML (2017): Effects of the spatial configuration of trees on urban heat mitigation: A comparative study. Remote Sensing of Environment 195, 1-12

Zhu N, Wang C, Zhou H, Li M (2003): Analysis on instantaneous spatial pattern of thermal force field in Harbin. Chinese Journal of Applied Ecology 14, 1955-1958 


\section{Figures}

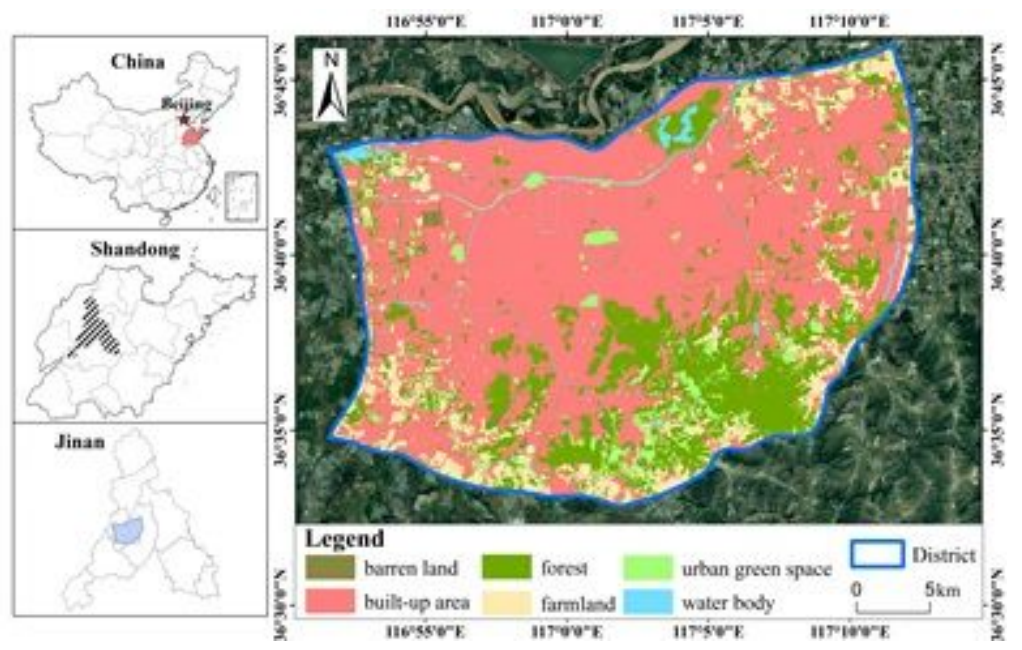

\section{Figure 1}

Map of the study area. Note: The designations employed and the presentation of the material on this map do not imply the expression of any opinion whatsoever on the part of Research Square concerning the legal status of any country, territory, city or area or of its authorities, or concerning the delimitation of its frontiers or boundaries. This map has been provided by the authors.

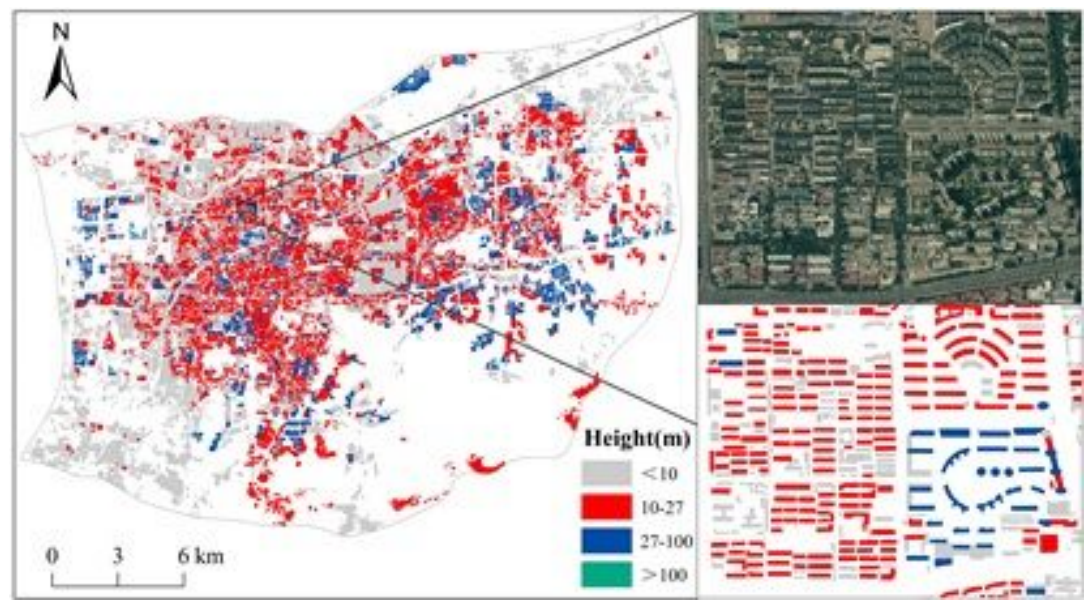

\section{Figure 2}

3D spatial distribution of buildings. Note: The designations employed and the presentation of the material on this map do not imply the expression of any opinion whatsoever on the part of Research Square concerning the legal status of any country, territory, city or area or of its authorities, or concerning the delimitation of its frontiers or boundaries. This map has been provided by the authors. 


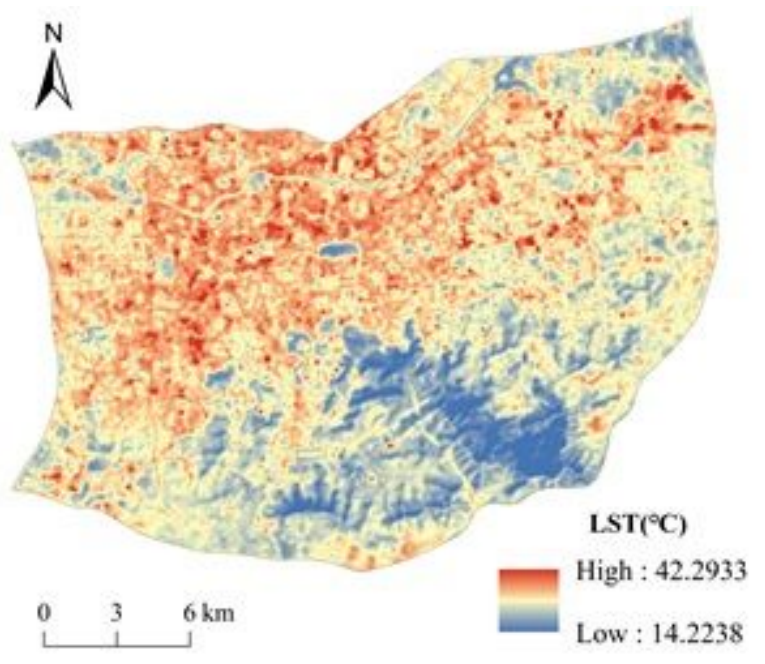

\section{Figure 3}

The sketch map of the overall LST distribution in the study area
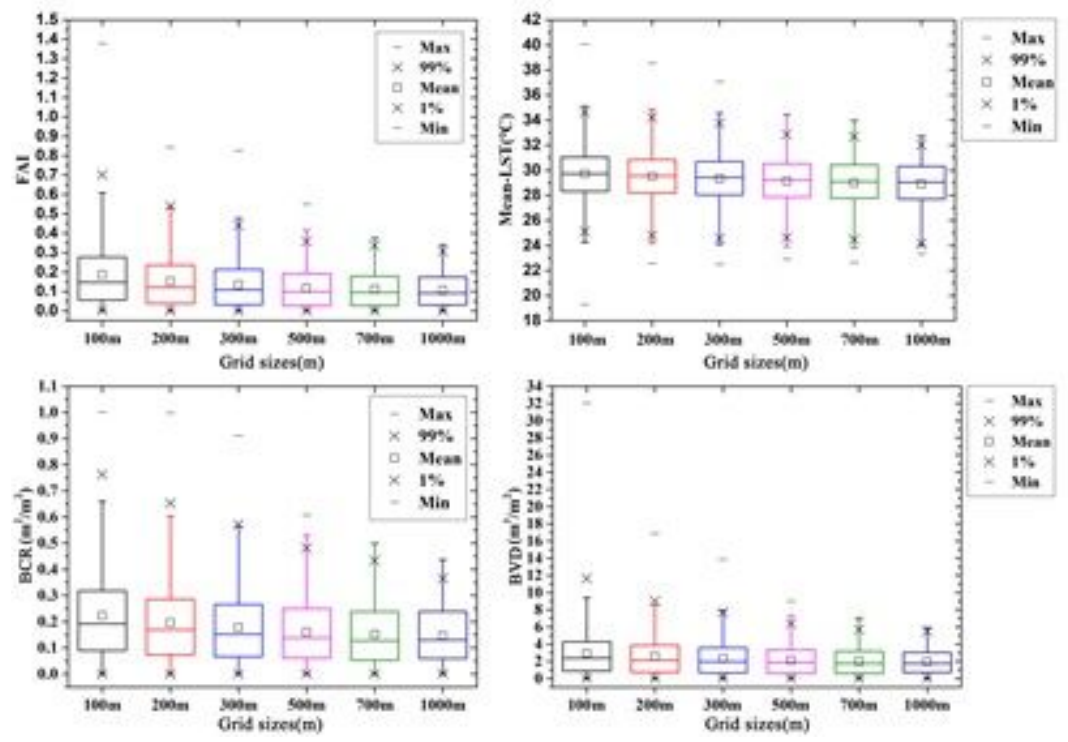

Figure 4

Box plot of LST and UMI distribution under different grid sizes 

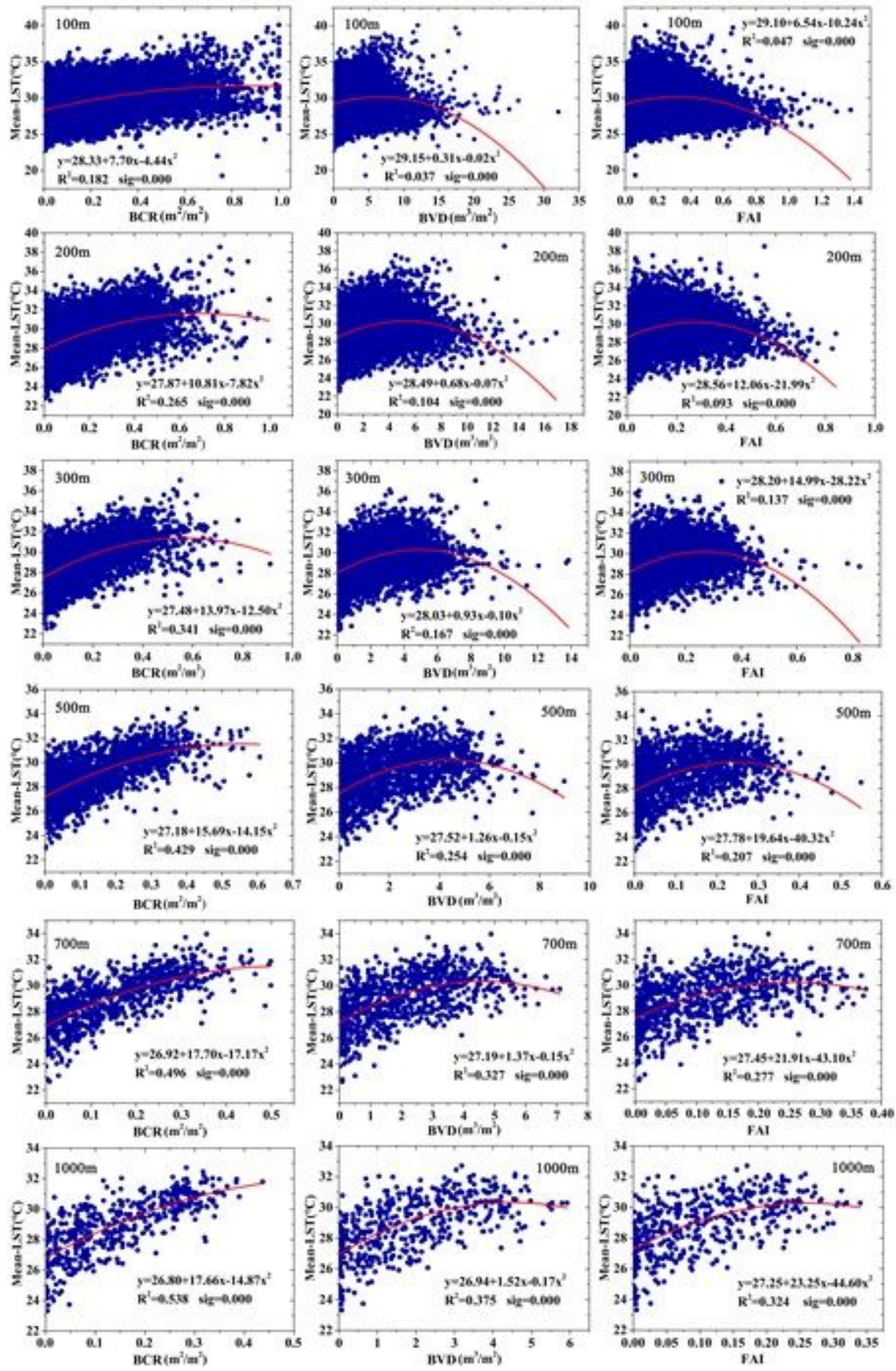

\section{Figure 5}

The scatterplots of LST in 2018 and 2D/3D urban morphology.
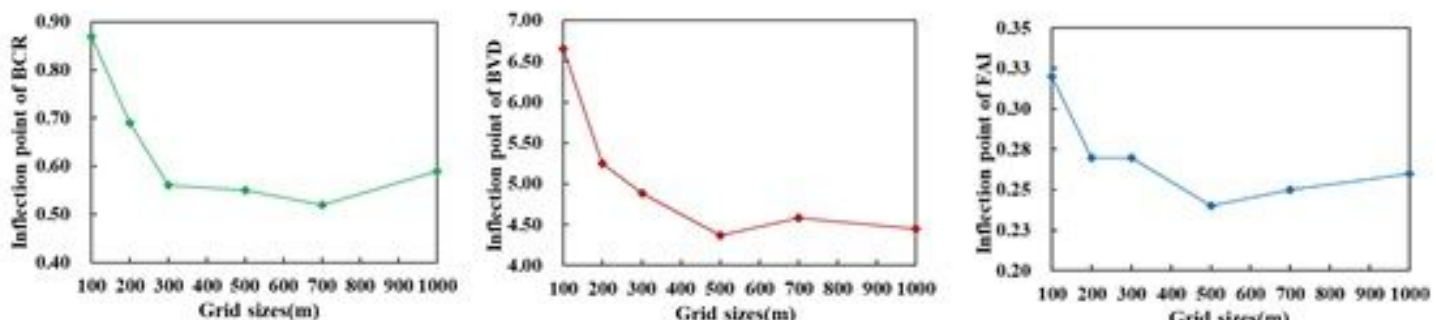

Grid sires(m)

Grid sires(m)

Grid sires(m) 
Figure 6

Inflection point of fitting curve between 2D/3D urban morphology and LST
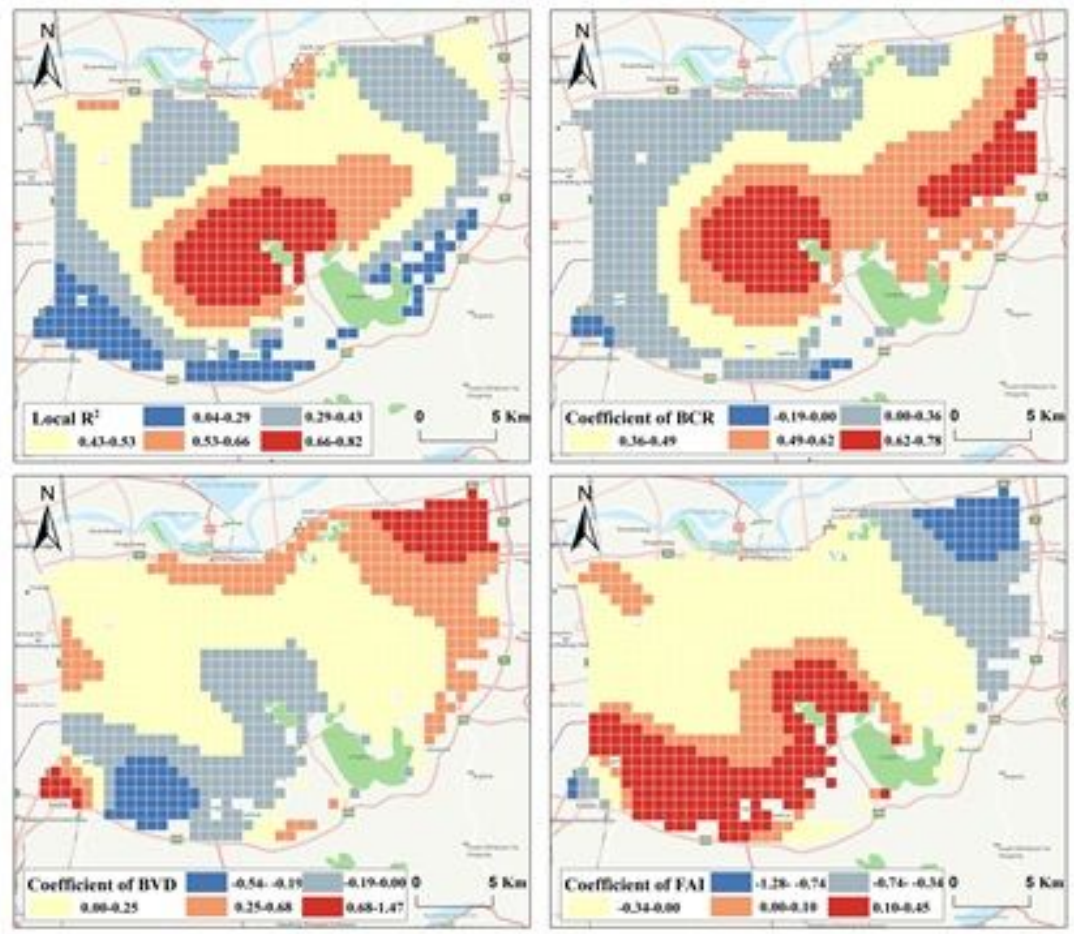

Figure 7

Schematic diagram of local R2 and regression coefficients of the GWR for urban morphology and LST. Note: The designations employed and the presentation of the material on this map do not imply the expression of any opinion whatsoever on the part of Research Square concerning the legal status of any country, territory, city or area or of its authorities, or concerning the delimitation of its frontiers or boundaries. This map has been provided by the authors.

\section{Supplementary Files}

This is a list of supplementary files associated with this preprint. Click to download.

- AppendixA.pdf 